\title{
Pengembangan Media Papan Tulis Interaktif Berbasis Graphical User Interface
}

\author{
Abtadi Tris Hamdani ${ }^{\star}$, Florentina Widihastrini, Umar Samadhy
}

Jurusan Pendidikan Guru Sekolah Dasar, Fakultas Ilmu Pendidikan, Universitas Negeri Semarang, Indonesia

\begin{abstract}
Info Artikel
Sejarah Artikel:

Diterima Oktober

2017

Disetujui November

2017

Dipublikasikan

Desember 2017

Keywords:

GUI; Media; Papan

Tulis Interaktif

Abstrak

Penelitian ini bertujuan untuk mengembangkan media papan tulis interaktif berbasis graphical user interface pada materi petunjuk penggunaan alat muatan Bahasa Indonesia kelas IV SD. Jenis penelitian ini adalah Research and Development (R\&D). Prosedur penelitian menggunakan waterfall yaitu analysis, design, implementation, testing, and maintenance. Populasi penelitian ini adalah siswa kelas IV SD Ngemplak Simongan 01 dengan teknik sampel jenuh yaitu seluruh siswa kelas IV SD Ngemplak Simongan 01. Teknik pengumpulan data menggunakan observasi, tes, angket dan dokumen. Teknik analisis data menggunakan analisis data produk, analisis data awal, uji t, uji gain, dan analisis data deskriptif. Hasil penelitian menunjukkan bahwa media papan tulis interaktif layak digunakan dengan skor penilaian komponen penyajian media 100, komponen isi materi 100 dan komponen kebahasaan 100. Media papan tulis interaktif berpengaruh terhadap hasil belajar dengan adanya perbedaan rata-rata melalui uji t sebesar 7,68 dan peningkatan ratarata (gain) sebesar 0,34435 dengan kriteria sedang. Aktivitas siswa memperoleh skor 354 dengan nilai 70,8 termasuk kriteria aktif pada pertemuan 1 dan memperoleh skor 480 dengan nilai 96 yang termasuk kriteria sangat aktif pada pertemuan 2. Simpulan penelitian ini adalah media papan tulis interaktif berbasis graphical user interface efektif digunakan pada pembelajaran Bahasa Indonesia materi petunjuk penggunaan alat dan meningkatkan aktivitas siswa.
\end{abstract}

\begin{abstract}
The aims of this research are to improve teachers skills, students activities and students achievement in social studies learning to the IV grade of SDN Kalisalak 01, Batang Regency through inquiry learning model by using adventureboard medium. This research is a classroom action research that is done in three cycles and conducted in SDN 01 Kalisalak, Batang Regency. The research subject is the fourth grade teachers and students. The data were collected and analyzed by using method data analysis technique of qualitative and quantitative analysis. The results of this study indicates that through the implementation of inquiry learning model by using Adventure Board medium can improve the quality of Social studies teaching and learning. The teachers' skills aspect shows that the percentage of cycle I gained $59.37 \%$ that is included enough category, the percentage of cycle II is gained $78.12 \%$ that is included good category, and in cycle III the success of percentage improves to $96.87 \%$ is included in the excellent category. On the other hand, the students activities on the the cycle I the percentage is $55.56 \%$ gains enough qualifications, the second cycle the percentage is $66.67 \%$ gains good qualification, whereas the third cycle the percentage increase to $83.33 \%$ gains good qualifications. In addition, the percentage students' classical thoroughness study cycle I is $55.56 \%$, while in the second cycle is $72.22 \%$, and the third cycle increase to $77.78 \%$. Based on the results it can be concluded that the inquiry learning model by using adventure boards medium can improve the quality of Social studies teaching and learning to the fourth grade of SDN Kalisalak 01, Kab. Batang Regency.
\end{abstract}

(C) 2017 Universitas Negeri Semarang

\footnotetext{
Alamat korespondensi:

J1. Srinindito Selatan VI No. 25 Kode Pos: 50148. Semarang

E-mail: abtaditrishamdani@gmail.com
}

ISSN 2252-6366 


\section{PENDAHULUAN}

Penyempurnaan permendikbud nomor 24 tentang Kompetensi Inti dan Kompetensi Dasar pelajaran pada kurikulum 2013 yang menyatakan bahwa tujuan kurikulum mencakup empat kompetensi, yaitu (1) kompetensi sikap spiritual, (2) sikap sosial, (3) pengetahuan, dan (4) keterampilan. Kompetensi tersebut dicapai melalui proses pembelajaran intrakurikuler, kokurikuler, dan/atau ekstrakurikuler. Bahasa Indonesia dalam pembelajaran kurikulum 2013 berperan dominan, yaitu sebagai pengantar materi dari semua sumber kompetensi kepada siswa. Dalam hal membangun wawasan, pengembangan tema dan menghubungkan satu tema dengan tema yang lain antar muatan pelajaran, bahasa Indonesia mampu berfungsi sebagai bahasa penyalur ilmu pengetahuan (Mulyasa, 2016:7).

Pembelajaran bahasa Indonesia bersifat kontekstual, sehingga melalui pembelajaran bahasa Indonesia siswa dilatih untuk menyajikan bermacam kompetensi secara logis dan sistematis untuk meningkatkan pemahaman mengenai materi yang disampaikan. Pada tema "Selalu Berhemat Energi", subtema "Manfaat Energi" kelas IV SD muatan Bahasa Indonesia, kompetensi dasarnya adalah "membandingkan petunjuk penggunaan dua alat yang sama dan berbeda" yang berupa pembuatan petunjuk penggunaan alat, membaca teks tersebut dan menyampaikannya dihadapan teman-teman lainnya (permendikbud, 2016:55).

Menurut survey terhadap guru-guru sekolah dasar mengenai wacana perubahan Kurikulum 2013 pada tanggal 1-5 Februari 2013 di Jakarta, Bogor, Bekasi dan Banten, sebanyak $75 \%$ guru tidak setuju integrasi IPA, IPS dengan Bahasa Indonesia. Fakta ini menunjukkan bahwa guru tidak siap atau tidak yakin dengan tematik-integratif, walaupun sebanyak $75 \%$ guru-guru sudah paham mengenai tematik integratif sebab selama ini tematik-integratif sudah dilaksanakan di kelas rendah (Hidayat, 2013:5-6).

Permasalahan muatan Bahasa Indonesia tersebut juga masih terjadi di Sekolah Dasar. Berdasarkan data pra penelitian yang dilakukan di Sekolah Dasar Ngemplak Simongan 01 melalui data dokumen dan wawancara dengan narasumber Guru Kelas IV ditemukan informasi bahwa pemahaman siswa mengenai materi yang disampaikan secara langsung dengan menggunakan ilustrasi masih belum maksimal karena media yang dipakai adalah papan tulis selain buku pelajaran. Papan tulis merupakan salah satu benda yang keberadaannya dibutuhkan dalam ruang kelas untuk proses belajar mengajar (Yuliarty, 2012: 1).

Papan tulis digunakan oleh guru dalam pembelajaran sehingga siswa terlihat antusias dan aktif ketika awal pelajaran, tetapi saat waktu sudah menunjukkan pukul 10.00 - 12.15 WIB, keaktifan siswa mulai berkurang dibuktikan dengan hasil observasi peneliti melalui catatan lapangan di SD Ngemplak Simongan 01 yang dilakukan sebanyak 3 kali dengan berbeda hari menunjukkan setelah jam istirahat pertama pukul 09.00 WIB rata-rata 12 orang siswa yang menunjukkan tangan saat guru menanyakan suatu pertanyaan, sedangkan rata-rata 23 siswa tidak mengacungkan tangannya. Keindahan,kemenarikan dan adanya interaktivitas dalam suatu media pembelajaran merupakan sarana agar peserta didik tidak jenuh dalam mengikuti pelajaran dan efek yang diharapkan peserta didik yaitu dapat termotivasi dan mempermudah dalam menerima materi pelajaran (Fanny, 2013:1). Sementara itu hasil belajar bahasa indonesia materi petunjuk penggunaan alat siswa kelas IV di SD Ngemplak Simongan 01 menunjukkan 
bahwa dengan Kriteria Ketuntasan Minimal (KKM) 70 pada ranah kognitif $37,7 \%$ siswa dari 45 siswa mendapatkan nilai di bawah 70 , sedangkan pada ranah keterampilan $20 \%$ dari 45 siswa mendapatkan nilai di bawah 65 .

Berdasarkan latar bekalang tersebut, peneliti membatasi masalah dalam penggunaan media pembelajaran untuk meningkatkan pemahaman materi petunjuk penggunaan alat kelas IV SD yang membutuhkan inovasi dan perlu pengembangan media. Arda (2015:5) menyatakan bahwa media dapat didefenisikan sebagai sesuatu yang dapat digunakan untuk menyampaikan pesan, merangsang pikiran dan perasaan siswa sehingga timbul motivasi untuk belajar.

Pemilihan media pembelajaran harus disesuaikan dengan materi yang diajarkan dan kondisi siswa. Sehingga diharapkan media pembelajaran tersebut bisa membantu siswa memahami konsep materi yang diajarkan, bisa menciptakan suasana belajar yang menyenangkan (Rahmah, 2014:2).

Rumusan masalah secara umum dalam penelitian ini adalah bagaimana keefektifan, kelayakan, dan aktifitas siswa menggunakan media papan tulis interaktif berbasis graphical user interface pada materi petunjuk penggunaan alat muatan Bahasa Indonesia kelas IV SD?

Tujuan penelitian ini adalah menguji keefektifan, mengkaji kelayakan, dan mendeskripsikan aktivitas siswa menggunakan media papan tulis interaktif berbasis graphical user interface pada materi petunjuk penggunaan alat muatan Bahasa Indonesia kelas IV SD Ngemplak Simongan 01 Semarang.

\section{METODE PENELITIAN}

Jenis penelitian ini adalah Research and Development (R\&D). Sugiyono (2015:407) menjelaskan bahwa metode penelitian dan pengembangan adalah metode penelitian yang digunakan untuk menghasilkan produk tertentu, dan menguji keefektifan produk. Model pengembangan yang diguankan peneliti adalah menggunaka air terjun (waterfall). Waterfall adalah model yang dikembangkan untuk pengembangan perangkat lunak, membuat perangkat lunak yang berkembang secara sistematis dari satu tahap ke tahap lain dalam bentuk seperti air terjun (Bassil, 2012:2).

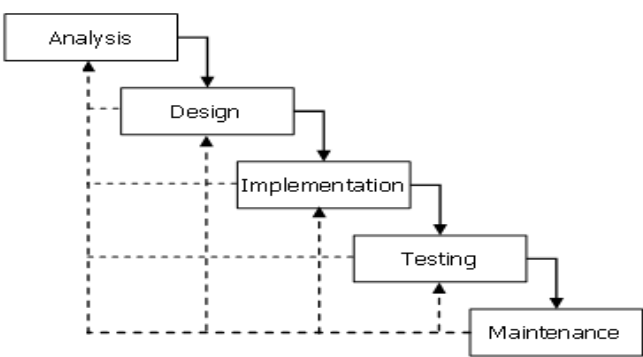

Gambar 1. Model Waterfall

Prosedur penelitian ini yaitu analisis kebutuhan, perancangan, pembuatan, pengujian, dan perawatan. Populasi penelitian ini adalah seluruh siswa kelas IV SD Ngemplak Simongan 01 dengan teknik sampel jenuh yaitu seluruh siswa kelas IV SD Ngemplak Simongan 01. Teknik pengumpulan data menggunakan observasi, tes, angket dan dokumen. Teknik analisis data menggunakan analisis data produk, analisis data awal, uji t, uji gain, dan analisis data deskriptif.

\section{HASIL PENELITIAN DAN PEMBAHASAN}

Hasil penelitian dan pengembangan media papan tulis interaktif berbasis graphical user interface mengkaji beberapa hal meliputi:

(1) perancangan pengembangan media papan tulis interaktif; (2) hasil pengembangan media papan tulis interaktif; (3) hasil analisis kelayakan, penyajian dan kebahasaan media papan tulis interaktif oleh ahli; (4) hasil analisis data akhir berupa keefektifan media media papan tulis 
interaktif dan aktivitas siswa dalam menggunakan media papan tulis interaktif.

\subsection{Pengembangan Media Papan Tulis Interaktif Berbasis Graphical User Interface}

Papan tulis interaktif terdiri dari beberapa komponen perangkat keras yang terdiri dari infrared pen, wii remote, dan bluetooth.

\section{Perancangan Infrared Pen}

Infrared Pen terdiri dari tempat spidol papan tulis putih yang sudah tidak terpakai, LED infrared, kabel, pegas dari besi, saklar tekan, resistor, baterai AAA 1,5 volt dan lem panas. Peralatan yang dipakai berupa solder, timah solder, dan alat lem panas. Gambar 2 merupakan skema pembuatan Infrared Pen ketika dirangakai menjadi satu kesatuan.

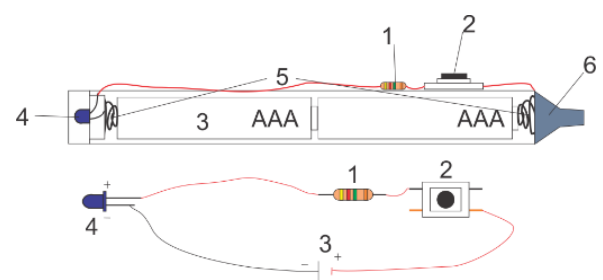

Gambar 2. Skema Infrared Pen

Keterangan:

1.Resistor (penghambat arus) $15 \mathrm{Ohm} 3$ Volt

2.Saklar Tekan

3. Baterai AAA 1.5 Volt

4.LED Infrared Tipe Vishay TSAL 6400

5.Kawat pegas untuk baterai

6.Spidol bekas

\section{Perancangan Dudukan Wii Remote}

Dudukan Wii Remote terdiri dari besi hanger pakaian, tutup pipa peralon yang berdimensi 4 inci, mur baut lengkap dengan ringnya, dan potongan besi holo (baja ringan). Peralatan yang digunakan adalah gerinda (pemotong), bor listrik, dan tang untuk membantu proses pembuatan lekukan besi hanger. Gambar 3 merupakan rancangan bentuk dudukan wii remote.

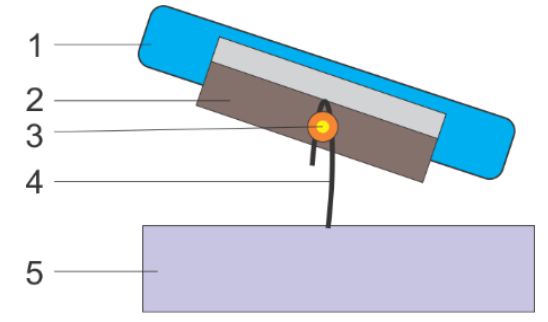

Gambar 3. Contoh Dudukan Wii Remote

Keterangan:

1. Wii Remote

2.Potongan besi holo (baja ringan)

3.Mur, baut, dan ring

4.Kawat bekas hanger

5.Tutup peralon 4 inci

Integrasi perangkat Infrared pen, Wii Remote, Bluetooth dan Laptop

Papan tulis interaktif dapat digunakan ketika semua komponen sudah disatukan. Proses penyatuan dilakukan dengan bantuan bluetooth dan perangkat lunak buatan pengembang pihak ke tiga, yaitu Pentabulous yang berfungsi sebagai penerjemah dari pergerakan infrared pen melalui pembaca sensor inframerah yang ada pada wii remote sehingga dapat difungsikan seperti mouse. Wii remote memiliki fitur utama yaitu kamera pixart infrared receiver yang berfungsi untuk menangkap gerakan dari pancaran gelombang sinar yang dihasilkan oleh infrared LED. Fitur lainnya yaitu bluetooth connector yang terintegrasi ke dalam wii remote yang dalam penggunaannya berfungsi untuk menghubungkan wii remote dengan komputer (Darmawan, 2010:8).

Penyampaian materi dilakukan melalui perangkat lunak presentasi dari Prezi, agar papan tulis interaktif dapat dimanfaatkan dengan baik, maka posisi sensor wii remote harus mencakup luasan sebesar $45^{\circ}$ ketika menyesuaikan ketentuan dari pabrikan. Tetapi peneliti melakukan perbaikan terhadap pembaca sensor tersebut agar dapat mencakup luasan lebih besar dari sebelumnya, yaitu dengan menambahkan lensa wide angle di depan sensor tersebut, 
hasil cakupan luas bertambah menjadi $360^{\circ}$. Sehingga pemasangan wii remote tidak lagi terkendala oleh posisi memasangnya. Pada gambar 4 diperlihatkan skema integrasi papan tulis interaktif.

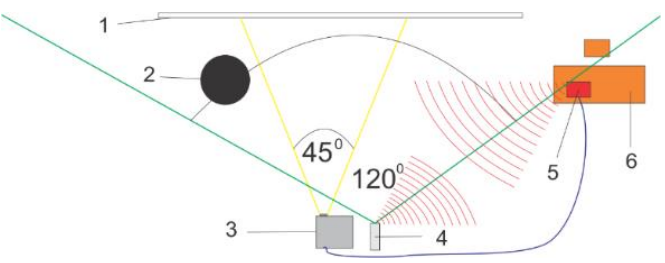

Gambar 4. Skema Integrasi Papan Tulis Interaktif

Keterangan:

1.Papan tulis konvensional/ layar proyektor

2.Pengguna

3.Proyektor

4. Wii Remote

5.Laptop/ PC

6.Meja dan Kursi Pengguna

3.2 Hasil Analisis Kelayakan, Penyajian Dan Kebahasaan Media Papan Tulis Interaktif Berbasis Graphical User Interface Oleh Ahli

Media papan tulis interaktif berbasis graphical user interface telah melalui proses penilaian kelayakan oleh ahli media, ahli materi, dan ahli bahasa dalam dua tahap. Hasil validasi penilaian media papan tulis interaktif berbasis graphical user interface tahap pertama disajikan dalam tabel 1 .

Tabel 1. Hasil Validasi Penilaian Papan Tulis Interaktif

\begin{tabular}{lc}
\hline $\begin{array}{c}\text { Komponen } \\
\text { yang di nilai }\end{array}$ & Skor \\
\hline Kelayakan Isi & 4 \\
Penyajian & 3 \\
Jumlah & 7 \\
Skor & 100 \\
Kriteria & Sangat Layak \\
\hline
\end{tabular}

Tabel 1 menunjukkan penilaian kelayakan media papan tulis interaktif berbasis graphical user interface tahap pertama meliputi dua komponen penilaian yang mendapatkan respon positif dari ahli media dengan skor 100 yang termasuk dalam kriteria sangat layak.

Media papan tulis interaktif berbasis graphical user interface yang lolos penilaian tahap 1, dilanjutkan penilaian pada tahap 2 yang terdiri dari komponen isi, materi, dan kebahasaan oleh para ahli. Hasil penilaian kelayakan media papan tulis interaktif berbasis graphical user interface oleh validator media, materi dan bahasa disajikan pada tabel 2 .

Tabel 2 Rekapitulasi Penilaian Kelayakan Media, Materi dan Bahasa Media Papan Tulis Interaktif Berbasis Graphical User Interface

\begin{tabular}{|c|c|c|c|c|}
\hline Penilai & Komponen & Jumlah & Skor & Kriteria \\
\hline \multirow{4}{*}{ Validator } & Penyajian & 16 & 100 & Sangat \\
\hline & Media & & & Layak \\
\hline & Isi Materi & 16 & 100 & $\begin{array}{c}\text { Sangat } \\
\text { Layak }\end{array}$ \\
\hline & Kebahasaan & 12 & 100 & $\begin{array}{c}\text { Sangat } \\
\text { Layak }\end{array}$ \\
\hline
\end{tabular}

Berdasarkan tabel 2 dapat dilihat bahwa penilaian oleh ahli media terhadap media papan tulis interaktif berbasis graphical user interface termasuk dalam kriteria sangat layak dengan skor 100. Ahli materi memberikan penilaian dengan skor 100 yang memiliki kriteria sangat layak. Ahli bahasa memberikan penilaian dari segi kebahasaan dengan skor 100 sehingga media papan tulis interaktif berbasis graphical user interface termasuk dalam kriteria sangat layak.

Berdasarkan uraian tersebut, maka media papan tulis interaktif berbasis graphical user interface dapat disimpulkan layak untuk digunakan sebagai media pembelajaran yang sejalan dengan penelitian Massimo Bosetti tahun 2011 berjudul "Interactive whiteboards based on the WiiMote: validation on the field". Dalam penelitian ini Bosetti menyimpulkan bahwa pembiayaan yang rendah dalam membangun perangakat Interactive whiteboards membuat $80 \%$ dari 10 guru sekolah dasar dan menengah merasa terbantu dengan adanya Interactive whiteboards dalam pengajaran. 


\section{Kefektifan Media Papan Tulis Interaktif Berbasis Graphical User Interface}

Keefektifan media papan tulis interaktif berbasis graphical user intarface diperoleh dari hasil belajar kognitif melalui tes formatif berupa pretest dan posttest. Peneliti melakukan uji peningkatan rata-rata untuk mengetahui peningkatan antara nilai pretest dengan nilai posttest setelah dilakukan perhitungan sebelumnya melalui uji t-test. Peningkatan antara nilai pretest dan nilai posttest diperoleh melalui perhitungan menggunakan rumus n-gain. Hasil uji peningkatan rata-rata data pretest dan posttest disajikan dalam tabel 3.

Tabel 3. Uji Peningkatan Rata-rata (Gain)

\begin{tabular}{cc}
\hline Kategori & Nilai \\
\hline Nilai Gain & 0,34435 \\
Rata-rata Pretest & 73,89 \\
Rata-rata Posttest & 80,27 \\
Selisih Rata-rata & 6,38 \\
Kriteria & Tinggi \\
\hline
\end{tabular}

Berdasarkan tabel 3 diketahui bahwa peningkatan rata-rata (gain) data pretest dan posttest sebesar 0,34435 dengan selisih ratarata 6,38. Peningkatan hasil pretest dan posttest penggunaan Media papan tulis interaktif berbasis graphical user intarface disajikan dalam bentuk diagram batang pada gambar 5 .

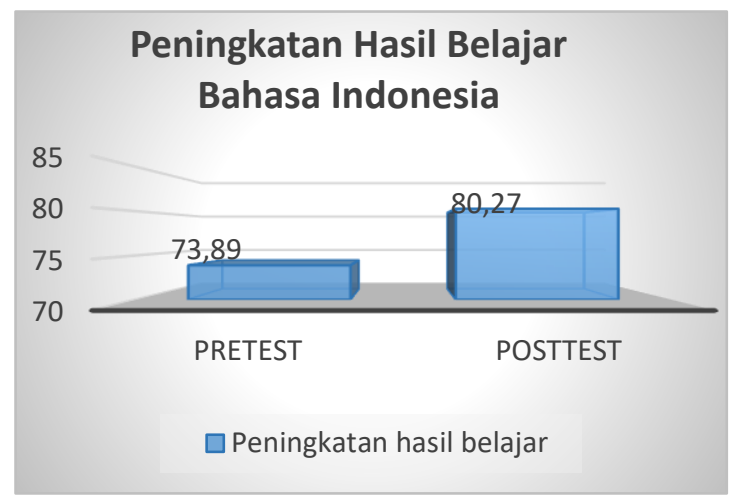

Gambar 5. Peningkatan Hasil Belajar menggunakan Media papan tulis interaktif berbasis graphical user intarface
Berdasarkan gambar 5 menunjukkan terdapat peningkatan hasil belajar yang dibuktikan dalam tes formatif berupa pretest dan posttest dengan perbedaan rata-rata sebesar 6,38. Peningkatan rata-rata menunjukkan bahwa media papan tulis interaktif berbasis graphical user intarface efektif digunakan dalam pembelajaran Bahasa Indonesia materi petunjuk penggunaan alat kelas IV SD Ngemplak Simongan 01 Semarang. Yusdianto (2012: 8) menyatakan bahwa papan tulis interaktif dapat menyimpan hasil pengajaran yang telah ditulis di layar sehingga siswa tidak bingung kalau kehilangan catatan atau lupa tentang materi apa yang telah disampaikan sebelumnya di dalam kelas.

\section{Aktifitas Siswa Menggunakan Media Papan Tulis Interaktif Berbasis Graphical User Interface}

Aktivitas siswa diperoleh melalui lembar pengamatan aktivitas siswa pada saat pembelajaran Bahasa Indonesia dengan materi petunjuk penggunaan alat saat pembelajaran berlangsung. Hasil uji deskriptif menunjukkan bahwa aktivitas siswa pada pertemuan 1 memperoleh jumlah skor 354 dengan nilai 70,8 termasuk dalam kriteria aktif dan pertemuan 2 memperoleh jumlah skor 480 dengan nilai 96 termasuk dalam kriteria sangat aktif. Hal ini sesuai dengan penelitian yang dilakukan oleh Sandra de Koster tahun 2014 berjudul "Interactivity with the interactive whiteboard in traditional and innovative primary schools: An exploratory study". Hasil penelitian ini adalah menunjukkan perbedaan interaksi dalam pembelajaran di dua sekolah yang berbeda. Satu sekolah yang telah diteliti ditemukan bahwa IWB menunjang aktivitas dan interaksi antara guru dan siswa dimana tidak selamanya yang diajarkan selalu sejalan dengan apa yang diinginkan oleh guru, penemuan yang paling mencolok adalah sekolahan menjadi lebih inovatif dalam 
$\begin{array}{llr}\text { melaksanakan } & \text { pembelajaran } & \text { karena } \\ \text { menggunakan } & \text { multimedia } & \text { yang } \\ \text { menguntungkan } & \text { bagi guru } & \text { yang } \\ \text { mengoperasikannya. } & & \end{array}$

\section{SIMPULAN}

Berdasarkan pengembangan media papan tulis interaktif berbasis graphical user interface untuk Bahasa Indonesia materi petunjuk penggunaan alat kelas IV SD Ngemplak Simongan 01 Semarang dapat disimpulkan bahwa media papan tulis interaktif dinyatakan layak oleh pakar materi, media dan bahasa dengan skor penilaian komponen kelayakan isi 100 , komponen penyajian 100 dan komponen kebahasaan 100.

Media papan tulis interaktif berbasis graphical user interface untuk Bahasa Indonesia materi petunjuk penggunaan alat terhadap hasil belajar siswa dengan perhitungan t-hitung yaitu 7,68 lebih besar dari dan $t$-tabel yaitu 1,68 dengan uji peningkatan rata-rata sebesar 0,34435 dengan kriteria tinggi. Penggunaan media papan tulis interaktif berbasis graphical user interface untuk Bahasa Indonesia materi petunjuk penggunaan alat dapat meningkatkan aktivitas siswa pada pertemuan 1 dengan nilai 70,8 termasuk dalam kriteria aktif dan aktivitas siswa pada pertemuan 2 dengan nilai 96 dengan kriteria sangat aktif.

\section{DAFTAR PUSTAKA}

Arda. 2015. "Pengembangan Media Pembelajaran Interaktif Berbasis Komputer untuk Siswa SMP Kelas VIII". e-Jurnal Mitra Sains, 3(1): 6977.

Bassil, Youssef. 2012. "A Simulation Model for the Waterfall Software Development Life Cycle". International Journal of Engineering \& Technology, 2(5): 2-7.

Bosetti, Massimo. 2011. "Interactive whiteboards based on the WiiMote: validation on the field". International Conference on Interactive Collaborative Learning, 14(11): 269273.

Darmawan, Fariz. 2010. "Perancangan Interactive Whiteboard Menggunakan Aplikasi Wii Remote Dengan Pendekatan High Touch Design Process". Jurnal Institut Teknologi Sepuluh Nopember, 1(1): 1-10.

Hidayat, Rais, dkk. 2013. "Survey Terhadap Guru-guru Sekolah Dasar Wacana Perubahan Kurikulum 2013". Rais of Journal, 8(2): 1-10.

Koster, Sandra de. 2013. "Interactivity with the interactive whiteboard in traditional and innovative primary schools: An exploratory study". Australasian Journal of Educational Technology, 29(4): 480-495.

Mulyasa, E.. 2016. Guru dalam Implementasi 2013. Bandung: Remaja Rosdakarya.

Rahmah, Fia Jannatur. 2014. "Pengembangan Media Pembelajaran Multimedia Interaktif Pada Kompetensi Dasar Jurnal Penyesuaian Perusahaan Dagang Kelas X AK". Jurnal Mahasiswa Teknologi Pendidikan Unesa, 1(1): 19.

Sugiyono. 2015. Metode Penelitian Pendidikan. Bandung: Alfabeta.

Yuliarty, Popy. 2012. "Pengembangan Desain Produk Papan Tulis dengan Metode Quality Function Deployment (QFD)". Jurnal Ilmiah PASTI, VI(1): 1-13.

Yusdianto, Andre. 2012. "Rancang Bangun Aplikasi Interactive Whiteboard Untuk Mendukung Pembelajaran Menggunakan Game Controlling". Journal of STMIK Surabaya, 1(1): 19. 